\title{
NOTAS PEDAGÓGICAS: LA CONTRIBUCIÓN DE MARIAZINHA FUSARI PARA LA FORMACIÓN DE PROFESORES EN ALFABETISMO MEDIÁTICO
}

\author{
PEDAGOGICAL NOTES: MARIAZINHA FUSARI'S CONTRIBUTION TO \\ TEACHER TRAINING IN MEDIA LITERACY
}

\author{
Márcia Barbosa da Silva \\ Universidade Estadual de Ponta Grossa, Brasil \\ https://orcid.org/0000-0001-8972-7713 \\ marciauepg@gmail.com \\ Gabriela Borges \\ Universidade Federal de Juiz de Fora, Brasil \\ https://orcid.org/0000-0002-0612-9732 \\ gabriela.borges0@gmail.com \\ Lucimara Cristina de Paula \\ Universidade Estadual de Ponta Grossa, Brasil \\ https://orcid.org/0000-0002-9556-7960 \\ lucrispaula@gmail.com
}

Recibido: 05-12-2019 Revisado: 23-12-2019. Aceptado: 05-02-2020

Resumen: El presente artículo se centra en las contribuciones de la educadora e investigadora brasilera Mariazinha Fusari para el alfabetismo mediático a partir de un análisis de sus notas pedagógicas. Considerada como una de las pioneras en los estudios de medios, infancia y formación de profesores en el Brasil, el texto busca rescatar su legado a través del análisis de sus notas como reveladoras de su pensamiento y del impacto que causaron en sus alumnos, orientados y colegas. El texto está dividido en tres partes, en la primera presentamos el concepto de alfabetismo mediático que orienta nuestra investigación, en la segunda parte presentamos un poco de la historia de Mariazinha contextualizando su pensamiento a partir de sus memorias. Finalizamos con la presentación de las notas pedagógicas y relatos sobre la importancia que tuvieron en la formación de las personas que los recibieron para la ampliación de la comprensión del contexto comunicativo escolar y sus implicaciones para la formación y el ejercicio de la ciudadanía.

Palabras claves: Formación, medios, alfabetización, profesorado.

Abstract: This article focuses on the contributions of Brazilian educator and researcher Mariazinha Fusari to media literacy based on an analysis of pedagogical notes. Considered as one of the pioneers in media studies, childhood and teacher education in Brazil, the text seeks to rescue its legacy through the analysis of its notes as revealing its thinking and the impact it had on its students, advisors and colleagues. The text is divided into three parts, in the first part we present the concept of media literacy that guides our research, in the second part we present a little of Mariazinha's story contextualizing her thinking from her memorial. We ended with the presentation of pedagogical notes and testimonies about how important they were in the training of the people who received them to broaden the understanding of the school communicational context and its implications for the formation and exercise of citizenship.

Key words: Training, media, literacy, teachers.

e-ISSN:2172-7910

Doi: http://doi.org/10.25267/Hachetetepe.2020.i20.7

Universidad de Cádiz 
Cómo citar este artículo: Silva, M.B., Borges, G. y Paula, L.C (2020). Notas pedagógicas: la contribución de Mariazinha Fusari para la formación de profesores en alfabetismo mediático. Hachetetepé. Revista científica en Educación y Comunicación, (20), 55-66. doi: http://doi.org/10.25267/Hachetetepe.2020.i20.7

\section{INTRODUCCIÓN}

El desarrollo técnico científico ha proporcionado avances en el conocimiento, sin embargo, las relaciones económicas que rigen la producción, la circulación y principalmente el destino de los conocimientos producidos, "a favor de quién y contra quién" como comentaría Freire (2004), han generado movimientos anticiencia y antiverdad. En este momento histórico hay intereses económicos y políticos que prosperan con la ignorancia, la intolerancia y el miedo como formas de control social. En este contexto, organismos como la UNESCO y la Comisión Europea han reforzado la importancia del alfabetismo mediático como un componente de la educación básica como medio de desarrollo de la propia ciudadanía.

El alfabetismo tiene un sentido de alfabetización más amplio, es decir, no se limita al acto mecánico de leer y escribir o a evaluar una cantidad de información adquirida, sino que se refiere a la capacidad de movilizarlas en la vida cotidiana para la toma de decisiones o la resolución de problemas. El alfabetismo mediático está relacionado con la capacidad para procesar información (Benavente, 1996), el análisis de elementos simbólicos, la reflexión, la criticidad. Para Reis (1997, p. 9 citado por Lopes, 2011, p.3), "la capacidad reivindicativa, el aumento del espíritu crítico, la propensión a adherirse a causas políticas y sociales es mucho mayor en quienes logran utilizar correctamente sus competencias de alfabetismo".

Cuando se relaciona con los medios (mídias), el alfabetismo se torna para la comprensión de la función social de los medios, es decir, el alfabetismo mediático va más allá de saber cómo operar los equipos y programas, significa comprender la función comunicativa que ejercen los medios y sus consecuencias para la formación de las identidades, la cultura y las decisiones políticas. Para Freire (2000), la cultura y la historia no son estáticas. El cambio es inherente a la cultura y a la historia, pero hay momentos en que se produce de forma acelerada. En la actualidad estamos presenciando la era de la Cultura Digital, de los medios para compartir, de las nuevas formas de ser y estar en el mundo, poblados por los medios (Hall, 1997). Buckingham (2005) considera que los medios de comunicación no nos colocan en contacto directo con el mundo, sino con versiones del mismo. En este sentido es importante que la escuela pueda desarrollar procesos educativos para comprender: ¿Cómo se producen estas versiones? ¿Cómo interfieren en la producción, elaboración y circulación de los significados? ¿Cómo interactuamos con estos significados? Y ¿Cómo nos constituimos como sujetos a partir de ellos?

Porcher (citado por Freire y Guimarães, 2003, p.143) afirma que "si alguien nunca ha aprendido a leer imágenes y textos, se beneficiará mucho menos de los medios de comunicación", enfatizando que las diferencias económicas y el control de los bienes culturales hacen que sean siempre las mismas personas las que tienen y disfrutan de los bienes culturales y, por lo tanto, están menos sujetas al control social. La solución no es negar la cultura, ni adherirse a los procesos de consumo cultural de forma acrítica. "No habría historia sin innovación, sin creatividad, sin curiosidad, sin libertad (...). No habría

e-ISSN:2172-7910

Doi: http://doi.org/10.25267/Hachetetepe.2020.i20.7

Universidad de Cádiz 
cultura ni historia sin riesgo (...) Puede que no sepa ahora qué riesgos tomo, pero sé que, como presencia en el mundo, corro riesgos" (Freire, 2000, p.30).

¿Qué riesgos corremos en la actualidad? Diríamos que, junto a la producción acelerada de conocimientos, corremos el riesgo de la ignorancia, o peor aún, de la inercia de estar encadenados a la caverna de Platón adorando sombras. Para el desarrollo de una Cultura Digital verdaderamente emancipadora es necesario recuperar la verdad como un valor, pensar la educación, la comunicación y el arte al servicio de un proyecto de humanización como diría Freire (1992), de cultivar el "ser más". En este contexto, el alfabetismo mediático asume un papel central en el desarrollo de la ciudadanía, y la participación social consiente y solidaria. En la legislación educativa brasilera las competencias mediáticas nunca tuvieron destaque especial, sin embargo, la reciente promulgación de la Base Nacional Curricular Común (BNCC) aporta en su constitución, especialmente en el capítulo sobre educación básica, una preocupación sobre esta cuestión.

La competencia general 4 hace énfasis en la capacidad de:

Utilizar diferentes lenguajes, verbal (oral o visual motora, como la lengua de señas, y escrita) corporal, visual, sonora y digital - así como conocimientos de los lenguajes artístico, matemático y científico, para expresar y compartir informaciones, experiencias, ideas y sentimientos en diferentes contextos y producir significados que conduzcan al entendimiento mutuo (Brasil, 2018, p. 9, fragmento nuestro).

De acuerdo con la competencia general 5 de la BNCC es necesario:

Comprender, utilizar y crear tecnologías digitales de la información y la comunicación de forma crítica, significativa, reflexiva y ética en las diversas prácticas sociales (incluidas las prácticas escolares) para comunicar, acceder y difundir información, producir conocimientos, resolver problemas y ejercer protagonismo y autoría en la vida personal y colectiva» (Brasil, 2018, p.9, fragmento nuestro).

Si asociamos estas dos competencias, privilegiando la comprensión y la expresión, podemos pensar en los medios no sólo como un producto de la cultura, sino también como un participante en la producción y circulación de la cultura y de la producción y expresión de identidades, que es algo que construimos desde la infancia. Esto también implica la formación de los profesores, ya que esta demanda era selectiva y ciertamente no incluía la educación de las clases o sectores popular.

Las competencias 6 y 7 descritas en la BNCC hacen énfasis en la capacidad de "valorar la diversidad de saberes y experiencias culturales", "argumentar sobre la base de hechos, datos e información confiable [...] con posicionamiento ético en relación con el cuidado de sí mismo, de los demás y del planeta", comprenderse "en la diversidad humana y reconocer las propias emociones y las de los demás, con autocrítica y capacidad para tratarlas", ejercer la empatía y el diálogo, la resolución de conflictos y la cooperación", "actuar de forma autónoma [...] sobre la base de principios éticos, democráticos, inclusivos, sostenibles y solidarios" (Brasil, 2018, p. 9-10). Todas estas competencias están en línea con las competencias mediáticas. "Será necesario discutir, en la práctica, la especificidad del tratamiento que se dará al proceso pedagógico, a partir del cual se

e-ISSN:2172-7910

Doi: http://doi.org/10.25267/Hachetetepe.2020.i20.7

Universidad de Cádiz 
pondrán en marcha las acciones de promoción de dichas competencias para ser implementadas" (Soares, 2018).

Desde 2014 hemos estado desarrollando investigaciones sobre alfabetismo y competencias mediáticas en contextos euro-americanos dentro de la RedAlfamed (1). Constatamos que tanto las nuevas generaciones como las más antiguas necesitan participar en procesos educativos para el desarrollo de competencias mediáticas, ya que el contacto con los medios digitales por sí solo no permite comprender en sí mismo las posibilidades tecnológicas, ni los procesos histórico-sociales que las generan. El sentido de la ciudadanía requiere no solo la capacidad de manejo, sino también la capacidad de interpretación y análisis crítico en las producciones de los medios, así como una expresión que considere y articule los intereses individuales y colectivos de las comunidades con miras al bienestar colectivo (Silva, 2011).

Con base en estos resultados el grupo se propuso desarrollar acciones para promover buenas prácticas. Una de las vertientes de este trabajo tiene como objetivo recuperar el legado de los educadores brasileros que han contribuido a la constitución de este campo de estudios en nuestro país. Es en esta sección donde el presente artículo se encuadra. Al investigar la vida y obra de Mariazinha Fusari, encontramos en los relatos y textos de sus alumnos, orientados y colegas, referencias a su práctica de escribir notas pedagógicas como una acción tanto formativa como afectiva que los marcó profundamente, direccionando sus comprensiones y prácticas para el alfabetismo mediático.

\section{METODOLOGÍA}

La metodología adoptada fue la investigación bibliográfica en un enfoque cualitativo. La investigación bibliográfica según Gil (2010, p.30), incluye el estudio de trabajos ya publicados y "aquellos que proponen analizar diferentes posiciones en relación con un tema determinado". Para Fazenda (1994, p.17), los estudios bibliográficos que se centran en un tema desde la perspectiva de perfilar un aspecto específico son muy importantes, "porque permiten que otros investigadores avancen en la profundización de elementos que no se explican adecuadamente ...". En el caso de la presente investigación, buscamos resaltar el pensamiento de Mariazinha Fusari y el papel de las notas como dispositivos formativos en su praxis. El enfoque bibliográfico nos permitió destacar en el pensamiento del autor la importancia de considerar el acto educativo como parte de la comunicación humana. En este artículo, presentamos solo una sección de la investigación, pero ya es posible percibir las contribuciones y la actualidad de sus trabajos. Según Bogdan y Biklen (1994, p.51): "el proceso de llevar a cabo una investigación cualitativa refleja un tipo de diálogo entre los investigadores y sus respectivos sujetos, ya que no son abordados por aquellos de manera neutral". Aquí, el diálogo que se establece es entre el investigador y el tema de las notas pedagógicas presentados por los autores de los textos estudiados, que a su vez resalta las notas como fragmentos de la comunicación personal dialogada que la autora mantuvo con los diferentes interlocutores, revelando la constante reflexión sobre ella; objeto de estudio y su práctica. 


\section{Mariazinha Fusari, un poco de su historia}

Proveniente de una familia de Minas Gerais, María Felisminda de Rezende (19401999) llegó cuando era una pequeña niña a San Pablo (São Paulo). Quizás por su estatura, o por la dulzura de su voz y su contacto con las personas, se convirtió en Mariazinha, y más tarde, como maestra, conoció al hombre que se convertiría en su esposo José Cerhi Fusari, y desde entonces fue más conocida como Mariazinha Fusari. (2) Conviviendo desde una temprana edad con el arte tanto en el ambiente escolar como en el familiar, presencio la llegada de la televisión al Brasil. El curso de formación de profesores en nivel medio era el camino natural de trabajo para las jóvenes de clase media y continúo su formación por este sendero. En ese momento, por aquella época en sus primeros ensayos didácticos preparaba cuidadosamente sus materiales pedagógicos, sobre los cuales reflexionaría más tarde:

(...) Yo todavía no sabía que aquello, más que soportes, equipos, "recursos", eran en un sentido más amplio, "textos" (icónicos, verbales, sonoros, audiovisuales) en cuyos "tejidos" siempre se entrelazan significantes - significados socio-histórico-culturales, nunca neutrales, debido al hecho que son seleccionados por sus creadores, seguidores o usuarios. Yo todavía no sabía que, como textos articulan imágenes, palabras, sonidos, tejidos en soportes, estos materiales eran (y son) medios de comunicación (medias) presentes entre profesores y estudiantes frente al conocimiento y que, por esta misma razón, eran (y son) participantes en sus producciones y mediaciones comunicativas sobre el mundo de la naturaleza, cultura, actitud, comprensión y perspectiva sobre los seres humanos (Fusari, 2001, p.11).

Fue en ese momento que tomó varios cursos de educación continua, algunos de los cuales fueron trascendentales, como el método "Lubienska Montessori" y un curso de filosofía con el Padre Lafrance, en el cual entro en contacto con las "notas filosóficas" cuidadosamente analizadas por el profesor" (Fusari, 2001, p.13). Tal vez haya iniciado así su intimidad con esta forma privilegiada de comunicación para la formación de profesores.

Estas experiencias la llevaron a querer graduarse en Pedagogía y aunque existían disciplinas dirigidas en audiovisuales para esa formación “(...) infelizmente, el proceso de producción social de la comunicación humana en la escuela con estos materiales en sus significados sensibles y estéticos más amplios no eran abordado en estas aulas". A finales de la década de 1960, en un curso de educación continua, comenzó a concebir los medios de comunicación escolares como participantes en un "proceso más amplio de comunicación humana" (Fusari, 2001, p.13). Aunque todavía era un entendimiento basado en una concepción lineal del tipo emisor-mensaje-receptor, permitió el desarrollo de:

(...) articulaciones con la educación escolar la cual paso a considerar como un proceso de comunicación de ideas, sentimientos, actitudes, habilidades frente al conocimiento del mundo, desarrollado por maestros en clase, con participación de realidades y representaciones vividas y concretas a través de los medios de comunicación (Fusari, 2001, p. 13). 
Entre 1971 y 1976 curso una Licenciatura en Artes Plásticas y Comunicación Visual, también tuvo la oportunidad de participar en un curso de actualización audiovisual de 40 horas en la "École Normale Superieure de Saint Cloud" en Francia y más tarde entre 1973 y 1975 tomó un curso más largo, sobre técnicas modernas de educación. Esa experiencia le proporcionó nuevas formas de pensar sobre lo audiovisual en la educación, además de aproximarla a los estudios sobre contenidos audiovisuales, especialmente en la televisión y sus conexiones con la educación que se estaba desarrollando en Francia en ese momento. Para su regreso al Brasil, ingresó al Instituto de Psicología de la Universidad de San Pablo (USP) como estudiante de posgrado en el curso de maestría y posteriormente completó su doctorado, ambos con un enfoque en estudios sobre Infancia, Televisión y Formación de Profesores. Durante este período, comenzó a enseñar en una facultad privada en San Pablo y poco después también se unió a la Facultad de Educación de la Universidad de San Pablo (FEUSP), ocupando cargos simultáneamente hasta 1988, cuando comenzó a dedicarse solo a este último.

Pionera, Mariazinha Fusari es una de las primeras maestras de la Facultad de Educación de la USP en percibir la importancia de la formación de educadores para tratar con los medios en el aula como objeto de estudio, entendiendo su valor social y su papel en la conquista de la ciudadanía. Sabe que los prejuicios y las opiniones distorsionadas deben superarse para que el profesor pueda enfrentar el derecho del alumno a conocer los medios y saber comunicarse a través de los mismos, saber cómo entender su lógica, su lenguaje, cómo criticarlos, cómo elaborar productos comunicativos con ellos, transmitir sus cosmovisiones, sus valores, su ética, su estética, compartir el poder de existir socialmente. Ve en la formación de maestros la clave para democratizar los derechos para disfrutar de estos saberes.

En los avances y retrocesos logrados, durante las prácticas formadoras de maestros para los medios y la producción comunicativa, los desafíos de llevar a cabo un trabajo más conciso permanecen (...). La comunicación humana con los medios tradicionales, nuevos y nuevísimos (en múltiples conexiones) en la educación escolar, y más de ella, debe continuar siendo objeto de contextualización, de prácticas y de reflexiones por parte de maestros y estudiantes en los cursos de Magisterio, Pedagogía y Licenciatura. Además, deben seguir siendo objeto de prácticas de investigación vinculadas a la formación del profesorado en estos cursos (Fusari, 1996, p.87).

Tanto en los textos como en los cursos y conferencias que impartió, Mariazinha Fusari enfatizó la investigación en formación y desempeño docente, investigación que se refirió a los medios, así como a la recepción y las formas de producir comunicación con ellos:

Durante la formación inicial para la docencia, en carreras de pedagogía, licenciatura y magisterio es necesario aprender a pensar y practicar comunicaciones mediáticas de una manera más significativa, comprometida y compartida con la ciudadanía, entendida aquí como conciencia y práctica de los derechos y deberes. Dichas prácticas de enseñanza y aprendizaje con los maestros requieren reflexión y crítica sobre los valores, estéticas, habilidades, actitudes comunicativas y educativas frente a los medios tradicionales, nuevos y novísimos. También requiere que los futuros profesores, además de repensar estas posturas, puedan articularlos con los proyectos y procesos de educación infantil, primaria y secundaria en nuestro país (Fusari, 1995, p.68).

e-ISSN:2172-7910

Doi: http://doi.org/10.25267/Hachetetepe.2020.i20.7

Universidad de Cádiz 
Nombrada como una de las personas que contribuyeron a la innovación en la educación brasilera (Ferreira, 2017), Mariazinha Fusari fue una investigadora adelantada a su tiempo, preocupada por la relación entre los medios, la infancia y la formación de docentes, pero no siempre reconocida dentro de los cursos de Pedagogía:

A finales del siglo XX, ese curso [o disciplina] ofertado en la formación de Pedagogía por la FEUSP se dirigía hacia su sexta fase, buscando producir y discutir "Comunicación, Multimedia y Educación", al realizar estudios sobre cultura multimediática, incluyendo informática, compromisos éticos y estéticos con la comunicación humana y con sus relaciones frente a cuestiones actuales. Infelizmente, la disciplina no está incluida en la parte obligatoria del plan de estudios, a pesar de los esfuerzos que algunos colegas y yo hemos hecho en sentido contrario. Quizás su historia aún no ha sido bien probada y, más que eso, ciertamente necesita ser mejor conocida y discutida en un ámbito más sustancial de formación de educadores contemporáneamente» (Fusari, 2001, p.20).

A fines de la década de 1980, Mariazinha se empeñaba en desenvolver cuestiones en la formación de profesores que se volvieron cruciales a principios del siglo XXI; la ética en las comunicaciones, la necesidad de pensamiento crítico y el compromiso con el bienestar colectivo, superando la individualidad tan exacerbada en estos tiempos. Aunque tenía una vida intelectual muy activa, Mariazinha solo publicó un libro en el área de comunicación y educación "El educador y el Dibujo Animado que el niño observa en la televisión", que trajo los resultados de la disertación de su maestría. Publicó capítulos en libros y numerosos artículos en revistas y anales de congresos nacionales e internacionales. Sin embargo, ese material aún es un pequeño adelanto de su trabajo como docente. En el siguiente ítem, discutimos su trabajo como maestra, formadora de futuros profesores y orientadora de investigadores.

\section{NOTAS PEDAGÓGICAS}

Quizás influenciada por su experiencia con las notas filosóficas mencionadas anteriormente, Mariazinha también adoptó este medio de comunicación en su práctica profesional de dos maneras: a) Como una estrategia para que los estudiantes se expresen mejor (libres de los rigores de la escritura científica, los estudiantes en sus cursos podían expresar sus primeras ideas sobre los medios y sus articulaciones con la educación, lo que les permitirá dedicarse más a la reflexión y a la aprensión de nuevo campo de estudio). b) En las correcciones de trabajos, lecturas de disertaciones y tesis e incluso con sus compañeros de trabajo como práctica formativa para alentarlos a expandir su potencial, sobre el cual vamos a centraremos en este artículo.

En una selección en homenaje a la educadora Silva (2001), atestigua que las notas sobre el trabajo de los estudiantes fueron parte de su práctica y muy esperadas por los alumnos como un momento formativo, además de la redacción del trabajo en sí, como podemos ver en la siguiente declaración:

Recuerdo cuando era su monitora y hacia parte de nuestras tareas acompañar algunas de las actividades de nuestros estudiantes. Cuando discutimos los primeros resultados, fui

e-ISSN:2172-7910

Doi: http://doi.org/10.25267/Hachetetepe.2020.i20.7

Universidad de Cádiz 
muy crítica. Pero ella, al darse cuenta de mi "dureza" de juicio, sonrió y me pidió que escribiera algunas notas para los estudiantes (como las que recibimos). Además, recomendó: "escribir algo que valore sus ideas y los aliente a continuar explorando el tema". Así que volví a las actividades con una mirada menos "dura" y más atenta a las posibilidades de crecimiento de cada uno (Silva, 2001, p. 43)

Este testimonio muestra la atención y el cuidado de Mariazinha por las reflexiones iniciales de los estudiantes y, al mismo tiempo, por la formación de su orientada de aquel momento, introduciéndola en la reflexión sobre las notas como actos formativos, no solamente como instrumentos pedagógicos, sino como medios de comunicación significativos para la formación de futuros docentes. Incentivando la investigación, Mariazinha desarrolló varios proyectos y actuó como co-orientadora en muchos otros, prestando su inteligencia generosamente. En todos ellos, llamo la atención de los autores sobre la necesidad de una comprensión más profunda de la relación entre comunicación y educación.

Se trata entonces de reflexionar y practicar continuamente acciones de comunicación y educación, articuladoras de las dimensiones humano-técnico-socio-políticas, las cuales entrelazan ciudades actuales más ciudades virtuales latinoamericanas situadas en el mundo, en el planeta, pero siempre con la intención de colaborar en la realización de mejores cualidades de humanización inclusiva para todos (Fusari, apud Cortelazzo, 2001, p.38)

Este fragmento tomado de una de sus notas para su entonces orientada Iolanda Cortelazzo, demuestra su preocupación y la convicción de la relación entre educación y comunicación era esencial para la formación y el ejercicio de la ciudadanía. Asumió esto, como un compromiso del cual el educador no podía desviarse, como se puede ver en otro fragmento de la misma nota:

Los compromisos, los deberes educativos de las personas que actúan en ciudades virtuales, ciberculturas, comunicativas son principalmente con la realización de los derechos y deberes de las personas en las ciudades físicas, actuales de tierra, agua, fuego, aire, personas, ciudadanos concretos como nos advierten Pierre Lévy, Neil Postman, Jésus Martín Barbero, Néstor García Canclini, Paulo Freire entre otros (Fusari, citado por Cortelazzo, p. 38).

La preocupación con la ciudadanía es quizás el punto más fuerte y diferenciador de Mariazinha en relación con otros investigadores en el área, como podemos ver en la finalización de la nota:

No debemos olvidar que, en todo el texto del relato de su tesis, es su (el nuestro) compromiso explícito e implícito - como educadora, comunicadora, investigadora y ciudadana - es el de, sobre todo, colaborar con la realización de mejoras en la calidad de la humanización de las personas - sin exclusiones - habitantes de las ciudades latinoamericanas actuales (Fusari, citado por Cortelazzo, 2001, p.38).

Su concepción de ciudadanía era amplia, tenía una profunda claridad de su dimensión en los aspectos más diversos de la vida y esa fue la brújula que guío su trabajo

e-ISSN:2172-7910

Doi: http://doi.org/10.25267/Hachetetepe.2020.i20.7

Universidad de Cádiz 
en la formación de profesores. Iolanda Cortelazzo comenta sobre la influencia en su carrera académica, de orientaciones como las presentes en sus notas:

Mariazinha orientaba, corregía los fallos, exigía disciplina, además valorizaba todos los hallazgos, las iniciativas, el trabajo tanto de sus estudiantes de pregrado y posgrado como de sus orientados. Sus palabras de aliento sirvieron como estimulantes que nos permitieron superar los obstáculos que se presentaban en el camino, iluminadores que nos guiaron para encontrar soluciones alternativas (Cortelazzo, 2001, p.39).

Para Mariazinha Fusari, la relación entre comunicación y educación en la formación de profesores se ubicó en dos ejes fundamentales: la comunicación escolar entre profesores y alumnos en la escuela y en la comunicación mediada por los medios dentro y fuera de la escuela. En el primer aspecto, les preocupaba cómo se producía la comunicación entre docentes y alumnos, cómo contribuía o no al desarrollo del conocimiento, la función primordial de la escuela:

¿Cómo es esta relación, esta interacción del profesor que se comunica con los alumnos comunicadores, con los conocimientos en artes, en portugués, en matemáticas, envolviendo cultura general básica, trabajo conjunto, ciudadanía responsable, compartiendo para la realización de una nueva mentalidad, pensando en la vida de calidad para todos (Fusari, 2001a, p.242)

En el segundo aspecto consideraba:

(...) es deseable y necesario que los docentes, desde su formación inicial y en la continuidad de su formación en el servicio, estudien medios y el desarrollo de la comunicación escolar con ellos en cursos y clases. Para eso, no es suficiente recolectar imágenes, sonidos, impresiones, audiovisuales (computarizados y/ o no), ni simplemente conocer sus técnicas. Es necesario aprender a elaborar e intervenir en el proceso de comunicación que ocurre entre profesores y estudiantes con esos medios, para ayudar en la realización de la ciudadanía contemporánea (Fusari, 1996, p.2).

En este sentido, el testimonio de Cortelazzo (2001), al comentar su nota, afirma:

Comunicadora en el verdadero sentido de la palabra, insistió en que la comunicación no podía ser hipodérmica, unidireccional. [...] insistía en que los emisores y receptores alternaban sus roles, ya que tenían historias de sus propias vidas y recibían e interpretaban cada mensaje desde su propio punto de vista, interlocutores que de alguna manera se influenciaban de forma recíproca (...)» Cortelazzo (2001, p.39).

El extracto anterior muestra cómo Mariazinha estaba preocupada por hacer que sus alumnos reflexionaran sobre la educación como un acto comunicativo, como lo indicó más tarde Cortellazo: "reflexioné mucho sobre mi acción como profesora, percibiendo que en ella existe una relación indiscutible entre Comunicación y Educación" (2001: 39). No solo los orientados, sino también los compañeros de trabajo se beneficiaron de sus notas. Su compañera en la redacción de libros sobre Arte y Educación, la profesora María Heloísa Correa de Toledo Ferraz dice que mantuvo las notas en letra pequeña características de la escritura de Mariazinha. Destaca una nota escrita cuando los

e-ISSN:2172-7910

Doi: http://doi.org/10.25267/Hachetetepe.2020.i20.7

Universidad de Cádiz 
Parámetros del Currículo Nacional (PCNs) en el área de artes, en la que Mariazinha se expresa sobre la importancia de la ética:

Es necesario dejar claro que la ética es una cuestión humana de las más importantes y que redimensiona los otros [temas curriculares] transversales (los cuales no poseen las mismas categorías de valor...) es necesario dejar claro, por ejemplo, que desde un punto de vista ético, queremos que el arte y el aprendizaje del multiculturalismo e interculturalidad sea con raíces en un humanismo crítico y de resistencia (y no en un humanismo liberal, acrítico y a-histórico (...) (Fusari, apud Ferraz, 2001, p.46).

Comprometida con una educación progresiva que favorezca la emancipación humana, Mariazinha reafirmó este compromiso entre sus pares a través de sus notas, como pequeñas dosis de reflexión que marcaron la diferencia en el entorno académico, en términos de proyectar cómo sería la educación para una sociedad menos desigual y más solidaria.

\section{CONSIDERACIONES FINALES}

En Brasil, concebimos notas como una comunicación informal y muy personal, en la cual escribimos mensajes cortos que por esta misma razón se centran en lo esencial. En los extractos anteriores, nos dimos cuenta de que este era un tipo de comunicación utilizada por Mariazinha Fusari para tratar con lo que era esencial para ella en la interfaz de comunicación y educación, pero sin descuidar la relación afectiva entre educador y estudiante o entre compañeros de trabajo. De esta forma, la autora no solo pronunció su visión sobre la comunicación como diría Freire (2004), sino que la experimentó haciéndola praxis, "entendida como una relación simbiótica entre la teoría y la práctica en equilibrio, para que una alimente a la otra, sin no hay jerarquía ni subordinación" (Silva, 2011, p.55). Una de las dificultades existentes en la formación de educadores es que, a pesar de tener dominio de las teorías de la educación/comunicación, no pueden hacer que estas concepciones se materialicen en su praxis (Freire, 2004; Silva, 2011). En el caso de Mariazinha, su reflexión se incorpora a su práctica al llamar la atención de sus estudiantes, asesores y colegas sobre el compromiso ético e histórico con la formación de ciudadanos que contribuye a la transformación y la reducción de la desigualdad social.

A finales del siglo XX, las revoluciones tecnológicas que influyeron en la comunicación y la educación aún no habían alcanzado el nivel de evolución que hoy tiene con internet de alta velocidad y teléfonos inteligentes (Smartphones), la interconectividad y las posibilidades de comunicación a distancia a través de imágenes. Aun así, podemos ver que las orientaciones de Mariazinha ya contemplaban cuestiones importantes para la alfabetización mediática, como la preocupación por la comunicación al servicio de la sociedad democrática, centrándose en la libertad de expresión, el acceso a la información y el conocimiento, así como la comprensión y acceso a modos de producción de comunicación humana (Wilson, 2013). Aunque en ese momento, el término alfabetismo no se conocía en Brasil, es posible percibir que sus fundamentos están presentes en el pensamiento de Mariazinha Fusari y se compartieron con sus estudiantes y compañeros de trabajo a través de sus notas pedagógicas. Las notas se mantienen como tesoros preciosos a los que se recurren cuando se necesitan beber de nuevo de la fuente del pensamiento de la gran maestra.

e-ISSN:2172-7910

Doi: http://doi.org/10.25267/Hachetetepe.2020.i20.7

Universidad de Cádiz 
Sus ideas y preocupaciones siguen siendo actuales y necesarias, especialmente con respecto a su concepción de la educación como un acto comunicativo, en la urgencia del profesor para considerar su práctica comunicativa en la escuela con y sin la mediación de los medios. También es importante y actual su reflexión sobre el papel social de los medios, su confianza en la capacidad de las personas para poder analizar las producciones que circulan en los medios y, sobre todo, su compromiso para ayudar a las personas a expresarse con los medios. ¿Qué diría hoy frente a la fiebre de las redes y los usos sociales no solidarios y antidemocráticos de las noticias falsas, qué diría de la fiebre entre niños y jóvenes por convertirse en youtubers, instagramers e influencers digitales? Ciertamente, su compromiso y reflexión serán extrañados, pero lo que dejó puede ser una guía en estos tiempos de avances tecnológicos y retrocesos humanos.

Notas

(1) AlfaMed - RedInteruniversitariaEuroamericana de InvestigaciónenCompetencias Mediáticas para laCiudadanía. Web: https://www.redalfamed.org/

(2) Aunque los cánones académicos favorecen la mención de los autores por su apellido, nos tomamos la libertad de usar su primer nombre en todo el texto, por lo que fue mejor conocida: Mariazinha.

\section{REFERENCIAS BIBLIOGRÁFICAS}

Benavente, A. (Coord) (1996). A Literacia em Portugal: resultados de uma pesquisa extensiva e monográfica. Lisboa: Fundação Calouste Gulbenkian.

Brasil. Ministério da Educação (2015). Base Nacional Comum Curricular. Brasília: MEC/SEB. Disponible en: http://basenacionalcomum.mec.gov.br

Buckingham, D. (2005). Educación en medios. Alfabetizacion, aprendizaje y cultura contemporánea. Barcelona: Paidós.

Cortelazzo, I. (2001). Colaboração, comunicação e educação para uma cidadania concreta. En Grinspum D. y Silva, M. (Orgs). Mariazinha de Rezende e Fusari por ela mesma e pelos amigos (pp. 37-41). São Paulo: Museu LazarSegal.

Ferraz, M. (2001). Lembranças de uma amizade. En D. Grinspum y M. Silva (Orgs) Mariazinha de Rezende e Fusari por ela mesma e pelos amigos (pp. 46-47).São Paulo: Museu LazarSegal.

Ferreira, P.(2017). Modelos ideais de educação mobilizaram brasileiros ao longo da história. Agência Brasil. Disponible en: http://www.encurtador.com.br/ouWZ1

Freire, P. (1992). Pedagogia da Esperança: um reencontro com a Pedagogia do oprimido. São Paulo: Paz e Terra.

Freire, P. (1996). Pedagogia da autonomia: saberes necessários à prática educativa. São Paulo: Paz e Terra.

Freire, P. (2000). Pedagogia da Indignação: cartas pedagógicas e outros escritos. São Paulo: Paz e Terra.

Freire, P. (2004). Pedagogia do oprimido. Rio de Janeiro: Paz e Terra.

Freire, P. y Guimarães, S. (2003). Sobre educação (Diálogos) V.2. Paz e Terra: São Paulo

Fusari, M. (1985). O educador e o desenho animado que a criança vê na televisão. São Paulo: Loyola.

Fusari, M. (1995). TV, Recepção e Comunicação na Formação Inicial de Professores em Cursos de Pedagogia. Perspectiva: Educação e Comunicação, 13(24), 67-91.

e-ISSN:2172-7910

Doi: http://doi.org/10.25267/Hachetetepe.2020.i20.7

Universidad de Cádiz 
Fusari, M. (2001). Memorial. En D. Grinspum y M. Silva, (Orgs). Mariazinha de Rezende e Fusari por ela mesma e pelos amigos (pp.7-27). São Paulo: Museu LazarSegal.

Fusari, M. (2001a). Comunicação, meios de comunicação e formação de professores: questões de pesquisa. En T. Porto (Org.). Saberes e linguagens de educação e comunicação. (p. 215-245) Pelotas: Editora e Gráfica Universitária - UFPEL.

Hall, S. (1997). A Centralidade da Cultura: notas sobre as revoluções de nosso tempo. Educação \& Realidade, 22(2), 15-46.

Lopes, P. (2011). Literacia(s) e literacia mediática. CIES-IUL. Disponible en: encurtador.com.br/rtAOT

Silva, M. (2001). Mariazinha, uma edu16cadora a frente do seu tempo. En D. Grinspum y M. Silva (Orgs). Mariazinha de Rezende e Fusari por ela mesma e pelos amigos (pp. 43-44). São Paulo: Museu LazarSegal.

Silva, M. (2011). O lugar do estudo das mídias na formação de professores numa perspectiva emancipatória. Tese (Doutorado em Educação) - Universidade Federal do Rio Grande do Norte, Natal.

Soares, I. (2018). Educomunicação, paradigma indispensável à renovação curricular no ensino básico no Brasil. Comunicação \& Educação, 23, 7-24. doi: 10.11606/issn.2316-9125.v23i1p7-24 